\title{
Bringing the Virtual to the Farmers' Market: Designing for Trust in Pervasive Computing Systems
}

\author{
Ian Wakeman ${ }^{1}$, Ann Light ${ }^{2}$, Jon Robinson ${ }^{1}$, \\ Dan Chalmers ${ }^{1}$, and Anirban Basu ${ }^{1}$ \\ 1 School of Informatics, University of Sussex, Brighton, UK \\ ${ }^{2}$ Communication and Computing Research Centre, Sheffield Hallam University, \\ Sheffield, UK
}

\begin{abstract}
Since pervasive computing applications are mostly designed to enhance existing social situations, such applications should take account of the trust relationships within the situation in their design. In this paper we describe the ethnographic approach we used to explore how trust is formed and maintained within a farmers' market, and how this understanding can be applied in the design of supporting applications. We then evaluate the applications using the same ethnographic approach, uncovering problems which would not have been visible with other evaluation techniques.
\end{abstract}

\section{Introduction}

In previous work we have developed computing support for a located shopping guide 9], and an augmented reality system for commenting on poster presentations [10. The consequent research question that emerged was whether such technologies could be used to support located shopping areas, and in particular, whether such systems could be deployed with a limited fixed infra-structure such as a street market.

Street markets are commonplace all over the world. They are characterised by the temporary nature of the stalls, although particular stalls are regular attendees, and used by a diverse range of customers. Farmers' Markets are a particular form of street market, emerging from the movement to encourage local produce and connect food producers directly to their customers. The eponymous farmers run stalls providing vegetables, poultry, meat and other produce. Such markets are typically not restricted to farmers, but do emphasise local artisan producers such as chutney makers and pie bakers.

Whilst they have a long history within the US, and arguably most French markets are already farmers' markets, the first Farmers' Market in the UK started in 1997 in Bath. The Lewes Farmers' Market was started in 1998 by the Common Cause Co-operative1, and has continued successfully to the present day. Common Cause now also run a smaller farmers' market in Hove once a month and

\footnotetext{
${ }^{1}$ http://www. commoncause.org.uk/
} 
were enthusiastic when we contacted them about the potential for deployment of support systems for markets.

When we deploy ubiquitous computing systems, we are often deploying in situations which already function well. In such cases, we must ensure that the existing processes and interactions are supported and enhanced rather than interrupted and disturbed. The approach often promoted in the literature is to take an ethnographic approach, where the existing sets of interactions are observed, analysed and used as input to the design process. In developing our application we have taken a pragmatic approach to capturing qualitative data, utilising accompanied shopping trips with a researcher acting as participant/observer to gain an understanding of how the market functions, analysing this data to inform the design process, and then using more accompanied shopping to evaluate the effectiveness of our deployed applications.

From our observations, it emerged that trust was the fundamental concept underpinning the interactions between the consumers and the stall holders, and any applications would have to build and support trust at a number of different levels. In the rest of this paper, we will first provide a brief overview of the various theoretical approaches to describing trust. We will then discuss how trust relationships are manifested and developed within the farmers' market, based on the evidence from our observations. We will then describe the technologies we deployed within the market, and discuss the effectiveness of our deployments.

\section{Theoretical Approaches to Trust}

In general trust is required within a transaction when there is the possibility of consequent loss or harm and the other party can influence whether the loss or harm is suffered. If the transaction proceeds, then the party at risk is trusting the other party will not intentionally cause harm or loss. Of course, within a farmer's market, the loss or harm is either a perceived monetary loss in feeling that the purchased item has been oversold - the same item is found significantly cheaper in a local shop - or the damage done to the fabric of everyday life when an item is found to be unfit for purpose - the special joint of meat bought for dinner turns out to be rotten.

Following the model of McKnight et al [7], trust can be examined across a range of constructs: Dispositional Trust; Trusting Beliefs; System Trust; Situation Decision to Trust; Trusting Intention and Trusting Behaviour. Dispositional Trust refers to the intrinsic traits of an individual that predispose them to trust. Over the course of their experience, people develop expectations about how people behave in any given situation, and these expectations will be carried through into similar new situations, forming the basis for initial beliefs. As a particular situation unfolds, a person will develop from these initial beliefs into Trusting Beliefs about the other individuals. These trusting beliefs are themselves likely to be formed of judgments about the others' ability and competence to perform, the others' benevolence and good will to the believer's well-being, the others' 
integrity and principles on which the other acts, and the predictability and consistency of action in the given situation.

As well as the generation of trusting beliefs, an individual will be influenced by their beliefs about the systems and societal structures in place to support interactions. As long as the situation appears normal (as in Garfinkel's definition of "normality" [2]) and subject to such structures as the legal system, and local assurance criteria such as membership of trade associations, then the individual will also have system trust to support their trusting intentions. Further, if they have become accustomed to a particular sort of situation, and a particular trusting decision has become habitual, their intention will become affected by a situational decision to trust.

The combination of the above cognitive and affective states will influence the individual to decide whether to trust the other, and their intention to behave in a trusting manner. A trusting intention requires that the individual is willing to depend on the others with confidence, even though negative outcomes are possible, whilst the trusting behaviour is the actual act of committing to the transaction.

\section{$3 \quad$ Methodology}

We first approached the market organisers explaining that we had a toolkit that could support customers and stallholders in communicating to each other, and that we wished to experiment within the market. The market is held monthly, so our timetable was as laid out in Table 1. Our approach is grounded in ethnographic study. Our initial visit consisted of conversations with all the stallholders and with the market organisers. In our second visit, an experienced ethnographic investigator accompanied two separate shoppers whilst they spent $£ 25$ in the market, followed by a debriefing interview. All the conversations were recorded, and interactions recorded through photos. In subsequent visits, the applications were deployed as described below, and our ethnographer again accompanied two separate shoppers. The shoppers were drawn from a pool of female volunteers (I 44 years old, W 41 years old, K 39 years old, H 22 years old), half of whom had familial responsibilities, and all of whom had attended other farmers' markets. $\mathrm{H}$ had previously worked on a food stall in a market.

Table 1. Deployment Timetable

February 2009 Initial visit; discussions with stallholders and market organisers

March 2009 Accompanied Shopping; Ethnographic study of two separate shoppers

April 2009 Shopping Lense Deployment; Accompanied shopping whilst using the Shopping Lense

May 2009 QR Code Deployment; Accompanied shopping utilising a QR Code reader on a mobile phone 


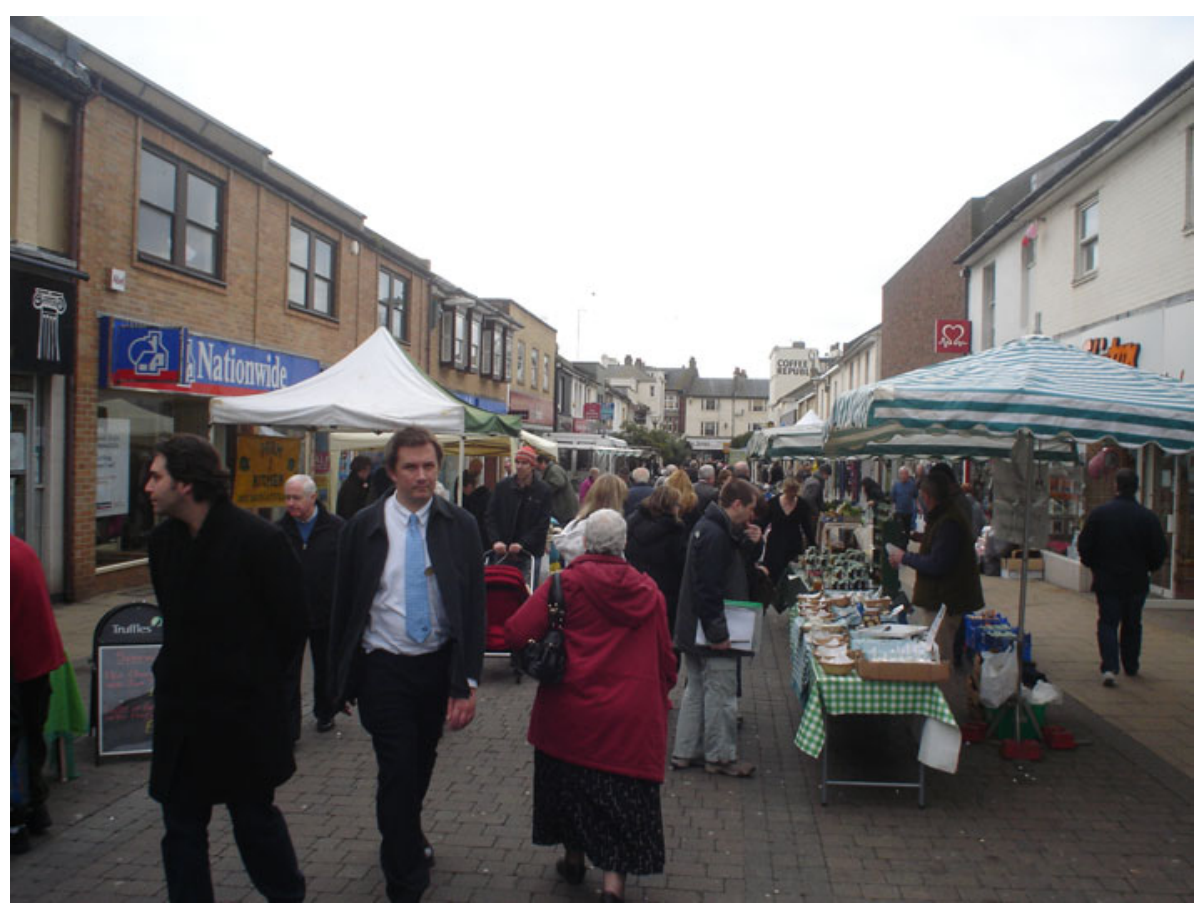

Fig. 1. Farmers' market view

The market is laid out as in Figure 1, with a mixture of stalls, ranging from simple tables (Figure 2) through to refrigerated vans (Figure 3).

\section{The Creation and Maintenance of Trust in the Farmers' Market}

In this section, we have studied the recordings, photos and notes from our accompanied shopping expeditions to understand how trust is formed and utilised within the market, using the theory of trust described in Section 2. Quotes from our shoppers come from the first accompanied shopping trips except where noted.

Farmers' markets emphasise the local nature of the products, and for the majority of the customers, this is the key attraction. As one of our participants claimed

Real people who have put together their own stuff from farms, or stuff they've made. Authenticity is really important. (I)

We have defined dispositional trust as the intrinsic likelihood that someone will trust in a particular situation. Given that an individual has to make an effort to actually attend a farmers' market, it would seem likely that they believe 


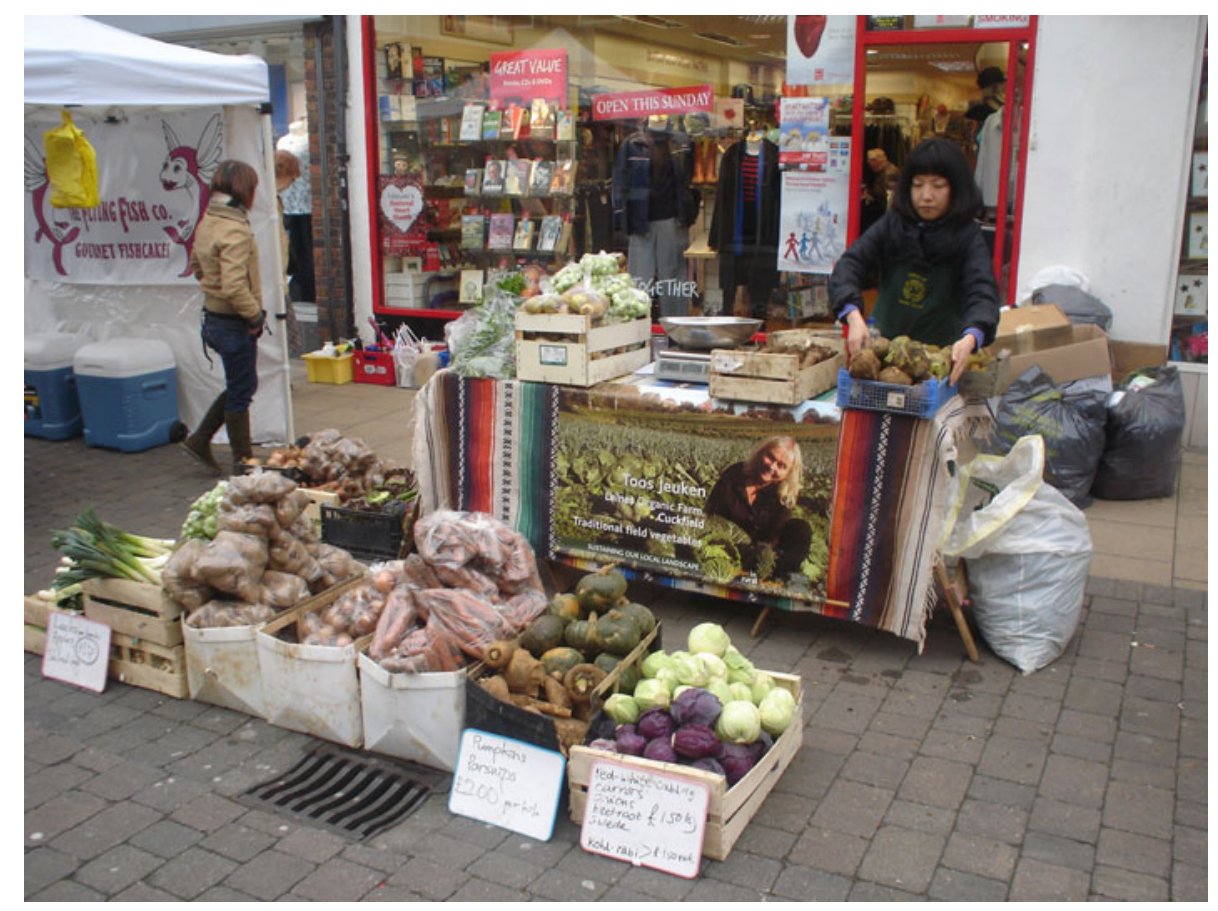

Fig. 2. Simple Stall

that local produce is worth the effort, and thus they are predisposed to trust the stalls within the market, unless stallholders provide counter-evidence. This follows similar arguments put forward by the studies on initial trust formation, such as those summarised by McKnight et al 8].

Our participants provided many insights into how the market and stall holders provide many different signifiers upon which to activate and build trust. Most significant was the development of conversations between the stallholder and their customers, both whilst negotiating at the point of sale, and from joining existing customers' conversations with the stallholder.

In one case, the stallholder of the pie stall invited other customers to join the negotiations of sale to provide bona fides of the quality of the product, and to discuss whether the product can be frozen. In consideration afterwards, the participant showed how these conversations can help induce trusting beliefs: "So if French people think its good food then it really must be a recommendation" (I). The other participant started a conversation with one of the couple currently being served by the butcher, exchanging tips about how to store roast beef. Such reassuring conversations help to generate trusting intentions about purchase decisions, developing trust that the decision will be well founded.

In Kirwan [6] there is an analysis of how markets are distinct from conventional shopping arenas in that they provide a temporary space for consumption. Indeed, they are often as much about theatre and participatory entertainment as about 


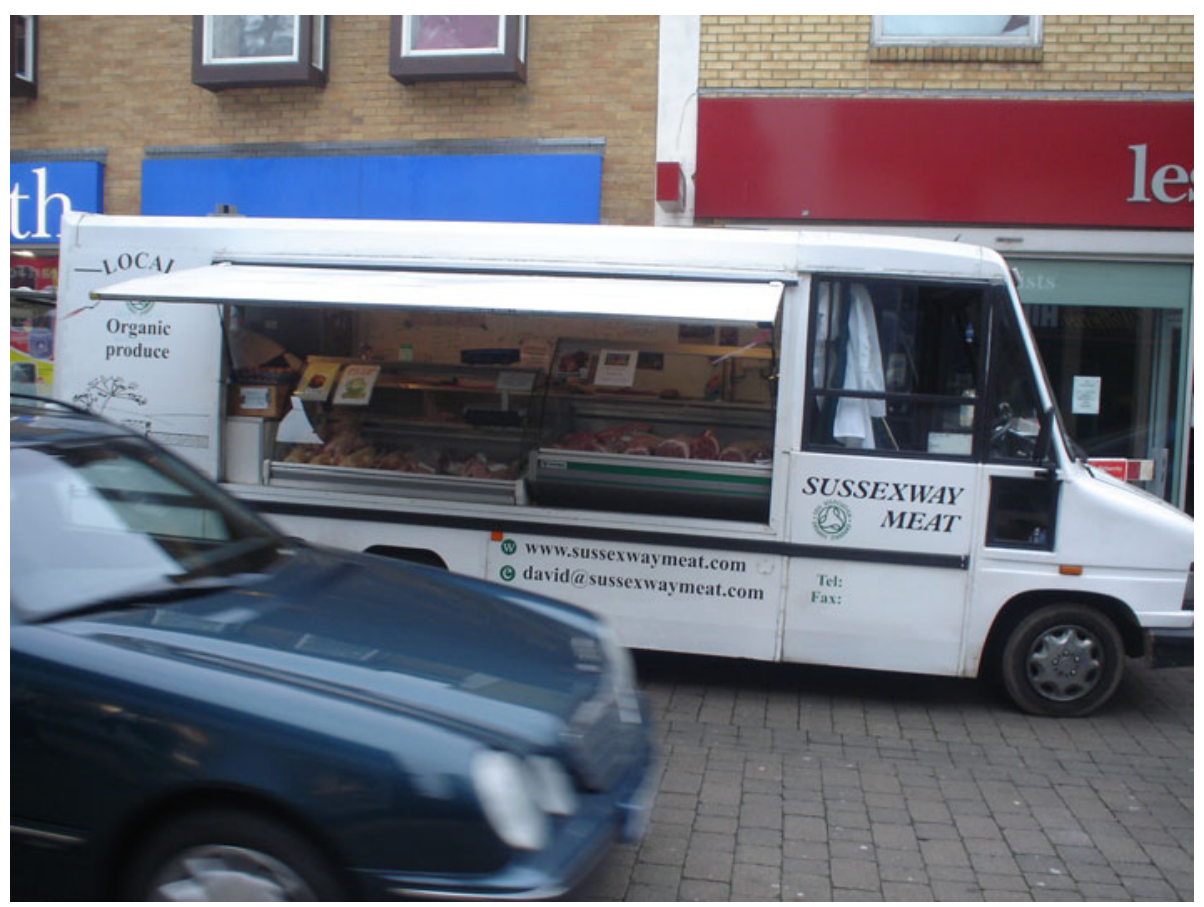

Fig. 3. Butcher's van

locating necessary items of consumption [4]. In Gregson's analysis of car boot sales [3, the market space is described as:

one where people come to play, where the conventions of retailing are suspended and where the participants come to engage in and produce theatre, performance spectacle and laughter.

Whilst the farmers' market is not quite so anarchic as a car boot sale, the interactions between stall-holder and customers can be viewed as creating a spectacle. For instance, as part of a conversation with four other customers, the stallholder selling pies started singing loudly to the tune of Don McLean's American Pie

Bye, bye, my lovely steak pies.

Have a pastie, have a pork pie, give my game pie a try

They're really good and they're lovely to buy...

Whilst this obviously entertained the immediate customers, it also generated interest from other passers-by, and thus attracted custom.

Overall, we found there were a number of subjects around which conversation formed. The most significant of these was the provenance of the produce, when customers would ask about the place and means of production. For instance, at a stall selling goats' cheese, we had the following exchange: 
Do you have your own goats? (W)

Yes, its a full time goat dairy farm... with about 400-450 on the farm

The stallholders understand that the key attraction of the farmers' market is that it's local. As one of our participant's commented, the farmer's market consists of "Real people who have put together their own stuff from farms, or stuff they've made. Authenticity is really important.". To that end, the stallholders not only discuss the provenance of the produce, but provide the history of how the company came to be. One stallholder proudly talked of this year being the "30th anniversary this year, and its our 8th year of doing farmers' markets", whilst another stallholder told a vignette of they came to be selling on the stall:

I'll tell you a little story about how I came to work for them. I went to a charity event and bid $£ 27$ for three pies. I bought them, put them in the fridge, ate them, they were so nice, and phoned him up went up to the farm, buying off them ever since, and eventually he says what do you do at weekends ... and now you know and I'm here and that's how it all started.

Besides contributing to the social nature of the market, such exchanges help to develop trusting beliefs in the customer, reassuring them that the products are local, and are produced in line with their expectations.

Another key set of topics for conversation is advice on what produce to choose, and how to prepare the produce for eating. At all of the stalls our participants visited, there was discussion about what they were looking for, whether the produce was for a special meal, and advice on cooking or how to present, whether the produce was venison, pork, chutneys or goats' cheese. Such conversations promote trusting intentions prior to purchase by showing that the stallholders are both interested in making sure the purchase decision is correct, and that they are knowledgeable about their products. As one of our participants reflected, "I trust them because they have investment in their produce" (W). However, there are differences in motivation across shoppers - our other participant reflected on how trust was engendered with a greater emphasis on the product:

[There's a] ...genuine sense of enthusiasm from stallholders, enables trust in the stallholder and by proxy to the product. But products come first - they look yummy and good and homegrown. The stallholders then back that up. (I)

Such conversations have other positive effects. One participant noted that " $M y$ self-esteem has has gone up through having a conversation that we're both interested in" (W).

Determining the Quality of a product in food consumption is a subject studied by consumer behaviourists and others. Products from supermarkets rely upon the uniform standards of quality generated by marketing and the other trappings of a consumer society. However, within a farmers' market, these uniform standards don't apply, since the necessary signage is absent in packaging and other shop displays. Instead, as Kirwan describes [6], the quality of products in farmers' markets is negotiated contingent upon conversation and place: 
In the case of FMs, the producers and consumers concerned are engaging in face-to-face interaction in order to create conventions of exchange which incorporate spatial and social relations that can replace 'uniform standards'.

The display of materials is set up to differentiate between the farmers' market produce and that available at conventional shops and supermarkets. Packaging is less sophisticated, emphasising the artisan nature of the product and the small scale production, in contrast to the slick packaging of supermarket produce. Produce such as cheeses and chutneys are all available to try, rather than solely those on special offer, encouraging the belief that the producer is confident you'll find something to like. Our shoppers found this to help in forming trusting beliefs - "You can try stuff out - its just all ere for you to have a go at" (I) - and indeed found the unsophisticated presentation a key piece of evidence for the products' quality.

A monthly street market is by definition a transient opportunity for consumers. The very appearance and presentation of the stalls signify the temporary nature of the stall. Stalls typically use a lightweight awning, and a covered table. Signage is attached to the awnings using market clips. Even the vans used by the meat suppliers, enabling the use of refrigeration equipment show the consumer that there is a time limited opportunity to get access to the stall. This can be seen as part of the "charm" of the market. Our accompanied shoppers displayed the same positions:

You can get that feeling that its real people selling their produce, actually because it quite thin, the displays are relatively thin. Its not absolutely piled up like a commercial thing

and that there are "Banners hanging behind stalls, there's a sense of homemade quality, the higgledy piggledy look." (I).

Kirwan also notes that the perception of quality is based upon "the build up of trust over time, which is facilitated by consumers being able to make direct connections with the place and nature of the good they are purchasing" [6]. In our observations, we found that customer I on her second visit to the stall was recognised and asked about how they had found the chutney they had bought previously, which was followed by the descriptions of similar chutneys.

Finally, there is an element of system trust. The norms of the farmers' market are primarily created by the organisers of the market. Producers who apply to run a stall within the market are required to fill out a form explaining their provenance chain, showing that their produce is primarily loca 2 and are subject to inspections by the market organisers. The organisers also work closely with the local agricultural college to promote organic and ethical production. Producers admitted to the market are therefore aware that they are in the market because of the origin of their produce and production ethics. Although the organisers

${ }^{2}$ The emphasis is on locality of produce but obviously producers of chutney can make use of ingredients sourced outside of the locality. 
conscientiously place small flyers describing the organisation and ethos behind the market, these are almost always ignored. However, in our observations, one stallholder described how stalls had to be certified to be in farmers' markets to one of our participants. Such system trust is reinforced as shoppers become more aware of the origins of the stalls and the market.

\section{$5 \quad$ Integrating Trust and Technology}

As described in [10, we have produced a toolkit for developing located applications for shopping environments. At the heart of our toolkit are the concepts of pseudonyms, groups, patterns and a pattern registry. A mobile phone is able to recognise a pattern such as a QRCode or a fiducial marker for augmented reality. The phone is then able to look up the pattern within the pattern registry, and retrieve data directly attached to the pattern and a list of associated comments. Each pattern or comment is owned by a pseudonym, allowing users to specify trust ratings on pseudonyms. Further, pseudonyms can belong to groups, allowing indirect policies to be specified based on group membership, using concepts from [12]. The system is designed so that authorisation of group membership happens offline and is subject to whatever checks are deemed necessary for the group's aims. Our system is designed to allow choice of a number of different approaches to order the list of comments returned for a pattern, based on whatever policy module is used for the application. The back end system is implemented within the Java EE framework, and is accessible over standard web services.

Given that the transient nature of the market stalls is integral to the perception of the farmers' market as local, we have adopted a low-tech approach to enabling the market for located computing applications by simply attaching A4 laminates of the patterns to the stalls by market pegs or Blu-Tack 3 , as show in Figure 4. From Section 4, it can be seen that the formation of trusting beliefs comes primarily from conversations between the stallholders and the customers. To this end, we have formulated an "AskUsAbout" application for use whilst people are queuing for their turn with the stallholder. For each stall we create a pattern, a group and an initial pseudonym as group member. The stallholder then can add whatever information they wish to the pattern, and add comments designed to act as primers for conversation when the user takes their turn with the stallholder. The policies of the users were primed so as to maximise trust in the stallholder's group comments, and minimise trust in other comments. The comments came from interviews with the stallholders, such as:

We have pet mince and free bones available. These are excellent value and really loved by dogs. Just $£ 1.50$, with reduced prices for regulars.

We also introduced a Visitors' Book application, allowing customers to add their comments about the stall. In this application, the policies were more flexible, only ordering comments based on whether the user was in the same group as the comment owner. An example of a comment left by our users was:

\footnotetext{
${ }^{3}$ Wikipedia describes Blu-Tack as " a versatile, reusable putty-like pressure-sensitive adhesive".
} 


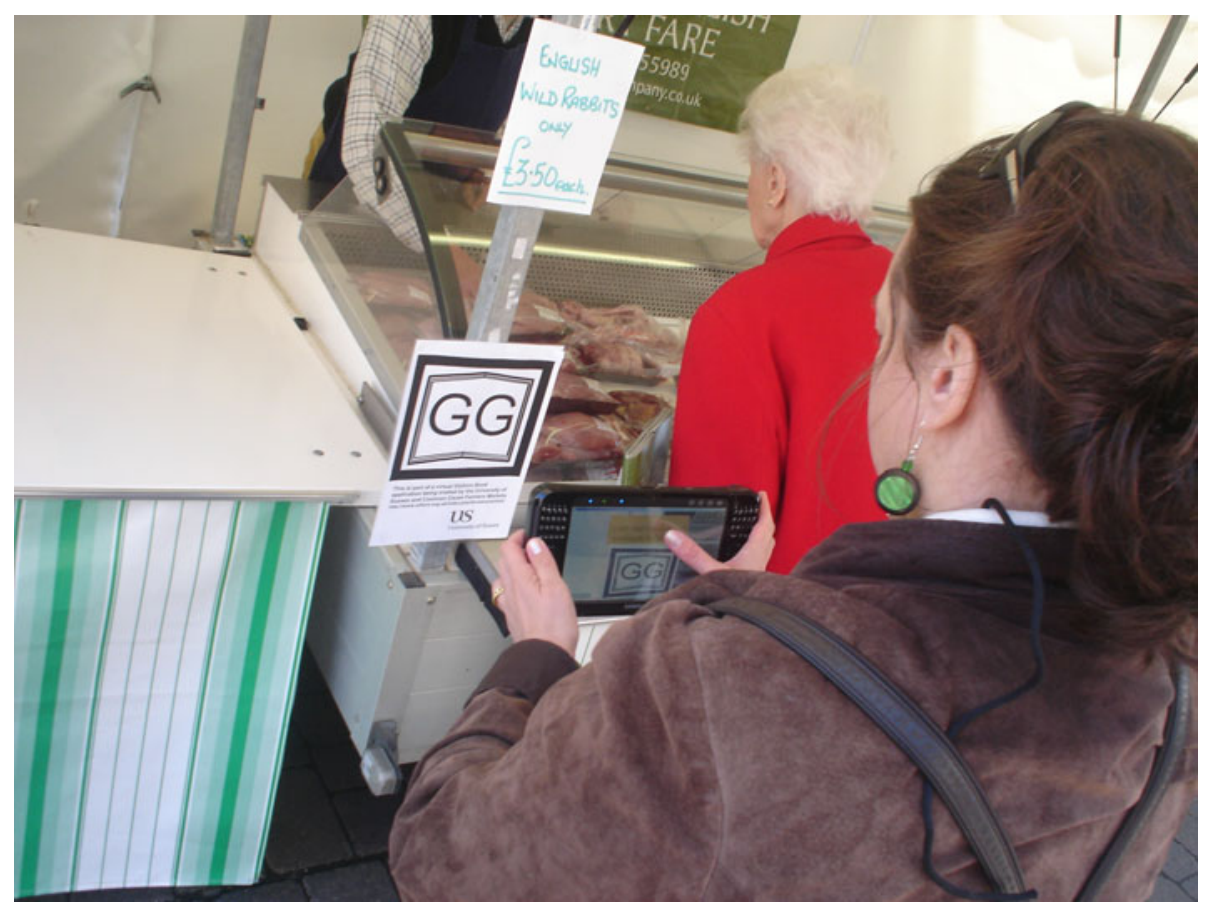

Fig. 4. A participant using the ARToolkit browser

We had some pork chops from David back in February, and they were delicious. Not only did they have the porkiest taste since we had Dotty down in Devon, they were cut so large that they were almost a roasting joint in their own right.

This application was motivated by the way that customers interact, asking each for advice and building trust about the stalls based on their prior experience.

We take advantage of the dispositional trust within the participants that everything and everybody within the market are local, and are thus all part of a shared community to reduce the level of authentication needed to use the system. Pseudonym registration requires nothing more than the creation of a unique identifier. The system is thus open to a number of sybil and denial of service attacks. However, since our trust policies are based on group membership, and group membership does require authentication, these attacks should not be very damaging. We also believe that the located nature of the application reduces the likelihood that such attacks would be mounted.

We implemented two possible front ends, using augmented reality to build a customised Shopping Lense, and using QR Codes [5] to encode the relevant URL to the back-end application, which utilises a normal web browser to display the interface rendered in HTML.

The Shopping Lense is built on the AR Toolkit [1, a mature toolkit for overlaying graphics upon a stream of video. The toolkit uses fiducial patterns, which 
are pre-compiled into recognisable patterns that the ARToolkit can recognise within frames of video. The Shopping Lense interface is based around a video view, highlighting patterns that are recognised, and annotating the pattern with the name that was attached to the pattern by its owner. We then display the most trusted anchors according to the user's policy around the pattern. By trial and error, given the expected viewing distance of up to ten meters, we decided to limit the number of anchors displayed around a pattern to four.

When an anchor is selected, the mode of the viewer is changed to that of a standard list box, displaying the text or URL associated with the anchor. All the other anchors linked to the pattern are displayed in a list, ordered by the trust rating generated in the back end. The level of trust in an anchor is indicated through colour coding (green being most trusted, orange neutral and red least trusted), the font weight of the text, and the size of the text. For this experiment, the Shopping Lense ran on an ultra mobile PC, as shown in Figure 4.

Whilst our initial aim was to port the Shopping Lense to a mobile phone platform, this proved impossible with the state of the art phone of last year, so we also built the QR Code version. The QR Code interface displays the anchors directly in HTML designed for the limitations of mobile phone browsers, but is otherwise functionally equivalent to the Shopping Lense. It should be noted that QR Codes were still rare in the UK in the first half of 2009, but we expect them to become more widespread and thus allows the software to be used by a wider population base in the future.

To populate the application databases, we gathered comments for the Visitors' Books from an emailed survey to members of our university and from our own experiences, whilst the information supplied within the AskUsAbout survey came from directly talking to the stallholders and from their websites.

\section{Evaluation}

Our evaluation comes from observing two of our participant shoppers ( $\mathrm{I}$ and $\mathrm{K}$ ) using the Shopping Lense, and then one month later observing another two using the a mobile phone using a QR Code reader. Since we have no participants who used both the Shopping Lense and the QR Code reader, we will not make any direct comparison between the two interface approaches.

It appeared both applications worked. Across all four participants, conversations were cued from reading the AskUsAbout information. The pattern would typically be that the shopper would read out the information to their accompanying shopper, when the stallholder would overhear and confirm the information. Discussion would then ensue. One shopper believed that the information helped increase her confidence in talking to the stall by providing her with background - its the "Kind of thing that's useful when you don't really know [the stall] at all." (H).

For the Visitors' Book, both $\mathrm{K}$ and $\mathrm{H}$ were prompted to buy products they wouldn't otherwise have purchased:

And I would, as I said earlier I think, have probably bought chicken or sausages because thats what my son likes to eat, but the fact that the 
kit mentioned pork chops made me think he really likes pork chops and I dont very often buy pork chops, so, yeah, just raised that possibility like you say $(\mathrm{K})$

and similarly

Its good, if I go to that [the application] first before looking at this [stall], then I'm immediately drawn to the pork chops, which is something I wouldn't normally buy... I suppose this is really good marketing $(\mathrm{H})$

$\mathrm{H}$ then reasoned that that the application worked because it was "A review at point of use which you wouldn't normally get in $y$ other way.". Given that a trusting belief is generated from the comment that is converted to a trusting intention of the purchase, it can be argued that the applications directly influenced the cognitive trust of the shoppers.

There were usability issues with both the Shopping Lense and the QR Codes. Although the UMPC is small, it still requires both hands to manipulate. Once the shopper was encumbered with bags, using the UMPC or paying became a struggle to coordinate all the necessary placing of bags. Although this became easier as the shoppers became accustomed to the kit,

But it didnt feel like a difficulty at that stall. I mean, I guess that was the third stall that Id bought something at and I think Id kind of.. I dont know why it was easier there, I cant remember now. Because that was the, the one stall where I didnt need to, I didnt think about it. (K)

it was noticeable that the phone was easier to use - "This is really intuitive I don't know this phone, but taking a photograph is really good" $(\mathrm{H})$. Underhill noted in [11] that when the hands are too full, the shopping spree is over. If we expect the shopper to then manipulate gadgets whilst holding bags, we will encounter problems. Indeed, the ballet of placing bags and kit on the stall to dive for the money to pay almost resulted in the UMPC being left behind.

We had problems with sunshine producing glare on the screen making it difficult to angle the UMPC so as to see the display - "I cant see anything here. Hmm, Im really struggling because of the sunlight to make it work." (K), with the shopper later referring to the need to move backwards and forwards to find a visible angle as "the dance". This may prove a major hurdle for the deployment of augmented reality in outdoors settings, since the UMPC has to be continuously pointed at the pattern to be viewed in real time. The QR Code deployment didn't suffer from these problems, since once the picture was taken, the returned HTML pages could be viewed in the shade of the stall, or by turning to position the body correctly.

Internet connectivity for our phones was occasionally problematic, and we were at the mercy of the idiosyncrasies of particular browser implementations. During the shop, one phone stopped getting $3 \mathrm{G}$ connectivity, so we had to switch to an alternative phone, with a different browser, and thus different approaches to scrolling the screen. 
Whilst our focus has been on delivering the technical solution to facilitate communication between stallholders and queuing customers, it became obvious from our deployment that the content of the comments is all important.

Wasnt the [information] the cue for you to have a conversation with the stall holders? (interviewer)

No, it wasnt... it felt like the information from the stall holder was, em, telling me something to persuade me to buy something, whereas I feel as though my conversations with stall holders usually are about, em, getting information that I want rather than information that they want to impart. $(\mathrm{K})$

The most successful comments contained the copy that was most informal, aligning itself with the authenticity of the market.

Positioning of the patterns could also present problems. The patterns had to be placed so that they were easily visible to the queuing customers, which could be difficult when queues would form irregularly.

One shopper raised a problem about whether the Visitors' Book was intended for comments about the experience of shopping and interacting with the stall, or about the experience of consumption. Our naive answer was that it was for both, but we plan to investigate in future work how to capture and provide comments at the appropriate time.

Finally, we saw several examples of the problems of combining the virtual world with a located market. Our shoppers wanted to talk to the stallholders and found the applications to be a hindrance, especially when they weren't accustomed to the gadget:

Hmm, I guess it kind of it feels more awkward for me, yeah, em, normally I would, my focus would be to try something and then probably talk to the stall holder and em, be more interpersonally focused than elsewhere which I feel focused elsewhere today

We saw suggestions that this may be a digital divide between how the younger and older shoppers would use the kit, where the younger shoppers would naturally explore the virtual world before conversation - "I don't know what they sell - I'm going to check out the bar code thing to see if that's any help" $(\mathrm{H})$ whereas the older shoppers all expressed a preference for conversation if possible - "My attention split between stallholder and and the kit".

\section{Conclusion}

Trust between people is fundamentally contingent on context and continually negotiated between people. The ways in which trust is signified and maintained are often implicit in a particular situation, and are not always obvious. If we build pervasive computing applications without regard for the subtleties of how peoples' relationships are supported, we run the risk of providing computing 
support that is at best ignored and may possibly break the existing trust relationships. In our investigation, we showed that conversations were the essential support for trust within the market. If our applications had attempted to replace conversation, we would have broken the social context of the market. A key lesson of this work is that the requirements for located computing require a deeper investigation of the social relationships, and that ethnographic investigation of some form is needed to explicate the context for design.

Further, evaluation of the effectiveness of the solution requires use of ethnographic techniques. Whilst our applications did work mostly as we expected, there were unforeseen problems that only emerged from the ethnographic analysis. The distinction between purchase and consumption experience was not clear from our first study, and would require further work to make the application work effectively. Whilst the AskUsAbout application provoked conversations with the stall holders, it only became apparent that some of the copy was alienating our participants through reflection with our ethnographer after the event.

Technically we found that adapting the toolkit to provide applications was relatively painless, and that it was essential to provide varying levels of technological sophistication for accessing the applications. Whilst augmented reality may become widespread in the coming years, the QR Code interface will remain much more accessible for the majority of the population without high powered mobile telephones.

In future work we are deploying the system as a communication channel for our university's catering service, where we hope to explore how a more digitally aware population will make use of a located application.

\section{References}

1. Billinghurst, M., Kato, H.: Collaborative augmented reality. Communications of the ACM 45(7), 64-70 (2002)

2. Garfinkel, H.: Studies in Ethnomethodology. Prentice Hall, Englewood Cliffs (1967)

3. Gregson, N., Crewe, L.: The bargain, the knowledge, and the spectacle: making sense of consumption in the space of the car-boot sale. Environment and Planning D 15(1), 87-112 (1997)

4. Holloway, L., Kneafsey, M.: Reading the space of the farmers' market: A preliminary investigation from the UK. Sociologia Ruralis 40(3), 285-299 (2000)

5. ISO(ed.) Information technology - Automatic identification and data capture techniques - QR Code 2005 bar code symbology specification. Number 18004 in IEC. ISO/IEC, 2 edn. (2006)

6. Kirwan, J.: The interpersonal world of direct marketing: Examining conventions of quality at uk farmers markets. Journal of Rural Studies 22(3), 301-312 (2006)

7. Harrison McKnight, D., Chervany, N.L.: The meanings of trust. Technical Report 94-04, Carlson School of Management, University of Minnesota (1996)

8. Harrison McKnight, D., Cummings, L.L., Chervany, N.L.: Initial trust formation in new organizational relationships. The Academy of Management Review 23(3), 473-490 (1998)

9. Robinson, J., Wakeman, I., Chalmers, D., Basu, A.: The North Laine shopping guide: A case study in modelling trust in applications. In: Proceedings of IFIP conference on Trust Management, May 2008, pp. 183-197. Springer, Boston (2008) 
10. Robinson, J., Wakeman, I., Chalmers, D., Horsfall, B.: Augmented reality support for poster presentations (submitted for publication, 2010)

11. Underhill, P.: Why We Buy: The Science of Shopping. Simon and Schuster, New York (2008)

12. Wakeman, I., Chalmers, D., Fry, M.: Reconciling privacy and security in pervasive computing. In: 5th International Workshop on Middleware for Pervasive and AdHoc Computing (MPAC 2007), Los Angeles, Ca (November 2007) 